\section{Journal of Biomedical and Pharmaceutical Research}

Available Online at www.jbpr.in

CODEN: - JBPRAU (Source: - American Chemical Society)

PubMed (National Library of Medicine): ID: (101671502)

Research Article

\title{
COMPARATIVE STUDY OF CUCURBITACEAE MEDICINAL PLANTS FOR PHYSICOCHEMICAL PARAMETERS
}

\author{
Yogesh Shivhare*, Alok Pal Jain
}

Sarvepalli Radhakrishnan University, Bhopal, Madhya Pradesh

Article Info: Received 17 August 2019; Accepted 28 October. 2019

DOI: https://doi.org/10.32553/jbpr.v8i5.664

Corresponding author: Yogesh Shivhare

Conflict of interest statement: No conflict of interest

\section{ABSTRACT:}

Modern research tool for evaluation of plant drugs are available today but physicochemical method is the one simplest and reasonable method for the assessment of quality and purity of crude plant materials. With the aim of drawing the physicochemical parameters of Cucurbitaceae family, the present study deals with leaves of all the selected Coccinia indica, Momordica dioica, Praecitrullus fistulosus, Trichosanthes dioica medicinal plants. The Obtained information will be used for further help in identifying the crude drug as potent therapeutic agents and assist in standardization for excellence and clarity.

Keywords: Physicochemical, Ash, Cucurbitaceae, Leaves

\section{INTRODUCTION}

Cucurbitaceae family is major source of medicinal agents since ancient time. Various plant parts including leaves and fruits of this family have been established for their pharmacological potential. The family Cucurbitaceae is an interesting and an unusual family of dicotyledons. It is a medium sized family consisting of about 120 genera and more than 800 species distributed predominantly in the tropical and subtropical regions of the new and old world [1]. Cucurbitaceae plants are of high economic value being a major source of food for man [2]. In the series of Cucurbitaceae plants, Coccinia indica, Momordica dioica, Praecitrullus fistulosus, Trichosanthes dioica are most of the excellent plants, gifted by the nature having composition of all the essential constituents that are required for normal and good human health. Coccinia indica is perennial, scandent or prostrate plant which is commonly known as Kundru. Momordica dioica is a cucurbitaceous popular summer vegetable. The Plant is commonly known as Kakora in Gwalior Chambal Division of M.P. Praecitrullus fistulosus, also known as Tinda is a famous vegetable of South Asia, known as apple gourd, Indian baby pumpkin and Indian round gourd. Trichosanthes dioica is cultivated extensively throughout the warmer parts of India, extending to Assam and E. Bengal to warmer parts of India. It is commonly known as Parwal in different areas.

Physicochemical evaluation of medicinal plants is a simple and reliable tool, by which complete information of the crude drug can be obtained. Sophisticated modern research tools for evaluation of the plant drugs are available today but physicochemical evaluation is one of the simplest and cheapest methods for establishing the correct identity of the source materials. Correct knowledge of crude drugs is very important aspect in preparation, safety and efficacy of the herbal product. Now-a-days medicinal plants have renowned medicinal significance and their usages are increasing day by day in routine life [3-5]. Different researches are going on to explore the beneficial, pharmacological and medicinal properties of herbal drugs. Hence, in this work an attempt was made for physicochemical evaluation of different cucurbitaceae medicinal plants.

\section{MATERIALS AND METHODS}

\subsection{Preparation of plant drugs}

Collected leaves of all the plants were identified by expert botanist. The leaves of Coccinia indica, Momordica dioica, Pracecitrullus fistulosus and Trichosanthes dioica were shade dried and 
Yogesh Shivhare et al., Journal of Biomedical and Pharmaceutical Research

converted into moderately coarse powder separately. Powdered drugs of all the plants were stored for further experimentation work.

\subsection{Evaluation of Physicochemical parameters}

Physicochemical parameters such as percentage of total ash, acid insoluble ash, water soluble ash and sulphated ash were calculated based upon standard procedures [6-9].

\subsubsection{Determination of total ash}

About $2 \mathrm{gm}$ accurately weighed powdered drug was incinerated in a silica dish at a temperature not exceeding $450^{\circ} \mathrm{C}$ until free from carbon. It was then cooled and weighed. The percentage $w / w$ of ash with reference to the air-dried drug was calculated.

\subsubsection{Determination of acid insoluble ash}

Ash is boiled with $25 \mathrm{ml}$ dilute $\mathrm{HCL}(6 \mathrm{~N})$ for five minutes. The insoluble matter collected on an ash less filter paper, washed with hot water and ignited at a temperature not exceeding $450^{\circ} \mathrm{C}$ to a constant weight.

\subsubsection{Determination of water-soluble ash}

Ash is dissolved in distilled water and the insoluble part collected on an ash less filter paper and ignited at $450^{\circ} \mathrm{C}$ to constant weight. By subtracting the weight of insoluble part from that of the ash, the weight of soluble part of ash is obtained. Percentage of water soluble ash was calculated with reference to the air dried drug.

\subsubsection{Determination of sulphated ash}

$2 \mathrm{~g}$ of powdered samples are taken in crucibles and ignited at $450^{\circ} \mathrm{C}$ in a muffle furnace until the material gets thoroughly charred. The crucibles along with ash are taken out in desiccators and cooled. $1 \mathrm{ml} \mathrm{H}_{2} \mathrm{SO}_{4}$ is added to each crucible in order to moisten the residue. Heat gently until white fumes was no longer evolved and ignites at $800^{\circ} \mathrm{C}$ until black particles were disappeared. The crucibles are removed from the muffle furnace and transferred to desiccators, cooled and weighed to give the sulphated ash content.

\subsubsection{Determination of moisture content}

Place about 5 to $10 \mathrm{gm}$ of powder accurately weighed in a tared evaporating dish. Place the loaded bottle in the drying chamber. Dry the test specimen at $105^{\circ} \mathrm{C}$ for 3 hours, and weigh. Continue the drying and weighing at half an hour interval until difference between two successive weighing corresponds to not more than 0.25 per cent.

\subsubsection{Determination of foreign matter}

The $50 \mathrm{gm}$ drug sample was spread in a thin layer, and the pieces of foreign matter were sorted out by visual examination. The powder of foreign matter was sifted through a 250-micron sieve. All portions of the foreign matter were pooled and weighed.

\section{RESULTS AND DISCUSSION}

\subsection{Determination of total ash}

The total ash in terms of powdered drug Coccinia indica, Momordica dioica, Pracecitrullus fistulosus and Trichosanthes dioica was found 10\%, 7.25\%, $9.40 \%$ and $8.50 \%$ respectively. Low total ash implies the crude plant has low inorganic components. The findings were shown in fig 1 .

\subsection{Determination of acid insoluble ash}

Acid insoluble ash with respect to powdered drug of Coccinia indica, Momordica dioica, Pracecitrullus fistulosus and Trichosanthes dioica was found $1.80 \%, 2.10 \%, 1.50 \%$ and $1.50 \%$ respectively. Acid insoluble ash values give an idea about the presence of Silica and Oxalates in drugs. The findings were shown in fig 2.

\subsection{Determination of water-soluble ash}

Water-soluble ash in terms of powdered drug of Coccinia indica, Momordica dioica, Pracecitrullus fistulosus and Trichosanthes dioica was found $4.10 \%, 3.80 \%, 3.0 \%$ and $4.4 \%$ respectively. Watersoluble ash is used to determine the amount of inorganic compounds present in herbal drugs or medicinal plants. The findings were shown in fig 3.

\subsection{Determination of sulphated ash}

Sulphated ash with respect to powdered drug of Coccinia indica, Momordica dioica, Pracecitrullus fistulosus and Trichosanthes dioica was found $3.80 \%, 4.20 \%, 4.25 \%$ and $4.80 \%$ respectively. Sulphated ash measures the amount of nonvolatile impurities present in organic substance. The findings were shown in fig 4. 


\subsection{Determination of moisture content}

Moisture content in terms of powdered drug of Coccinia indica, Momordica dioica, Pracecitrullus fistulosus and Trichosanthes dioica was found $0.25 \%, 0.40 \%, 0.10 \%$ and $0.20 \%$ respectively. Determination of moisture content indicates the medicinal use of the drug. Low moisture content is always desirable for higher stability of drugs. The higher or lower percentage of moisture indicates the existence of wet or dry climate which may favour the growth of microorganisms and in turn will result in deterioration of the crude drug. The findings were shown in fig 5 .

\subsection{Determination of foreign matter}

Foreign matter in terms of powdered drug of Coccinia indica, Momordica dioica, Pracecitrullus fistulosus and Trichosanthes dioica was found $0.25 \%, 0.50 \%, 0.20 \%$ and $0.35 \%$ respectively. Determination of foreign matter indicates the quality of the herbal preparations. Foreign matter should not be more than $2 \%$ as per standards. The findings were shown in fig 6 .
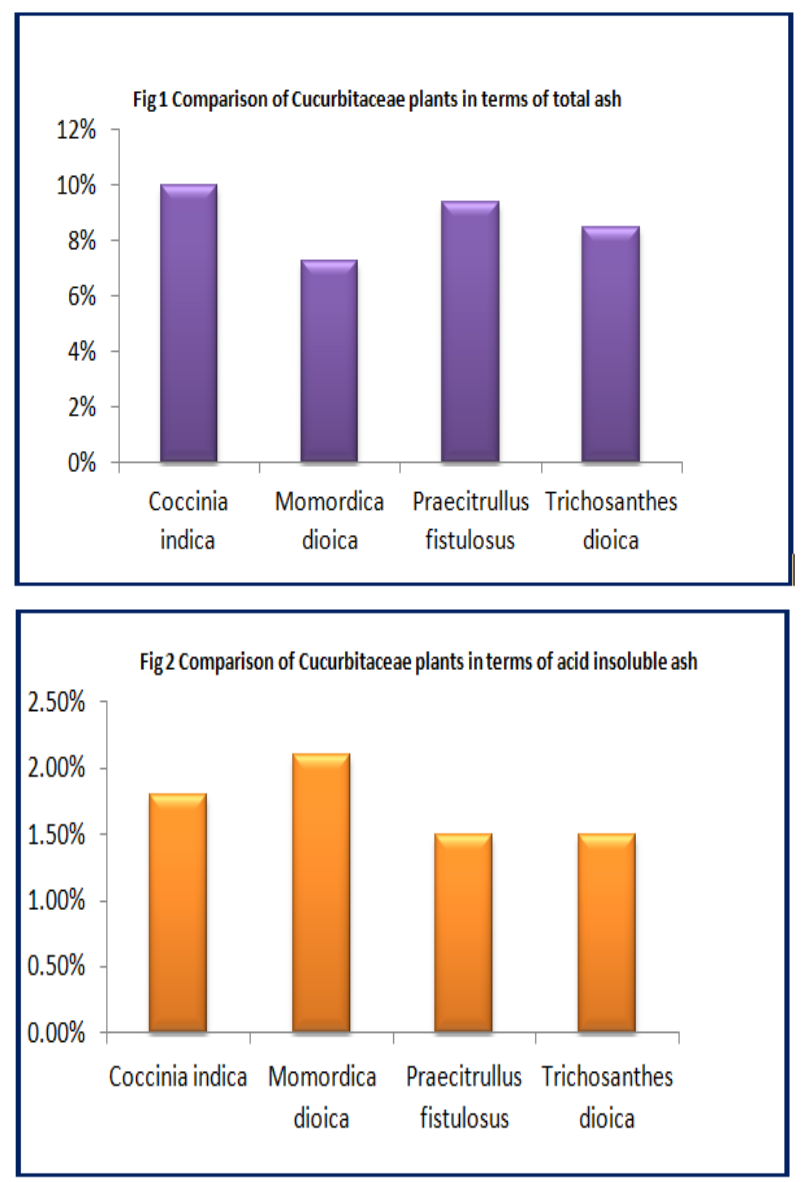
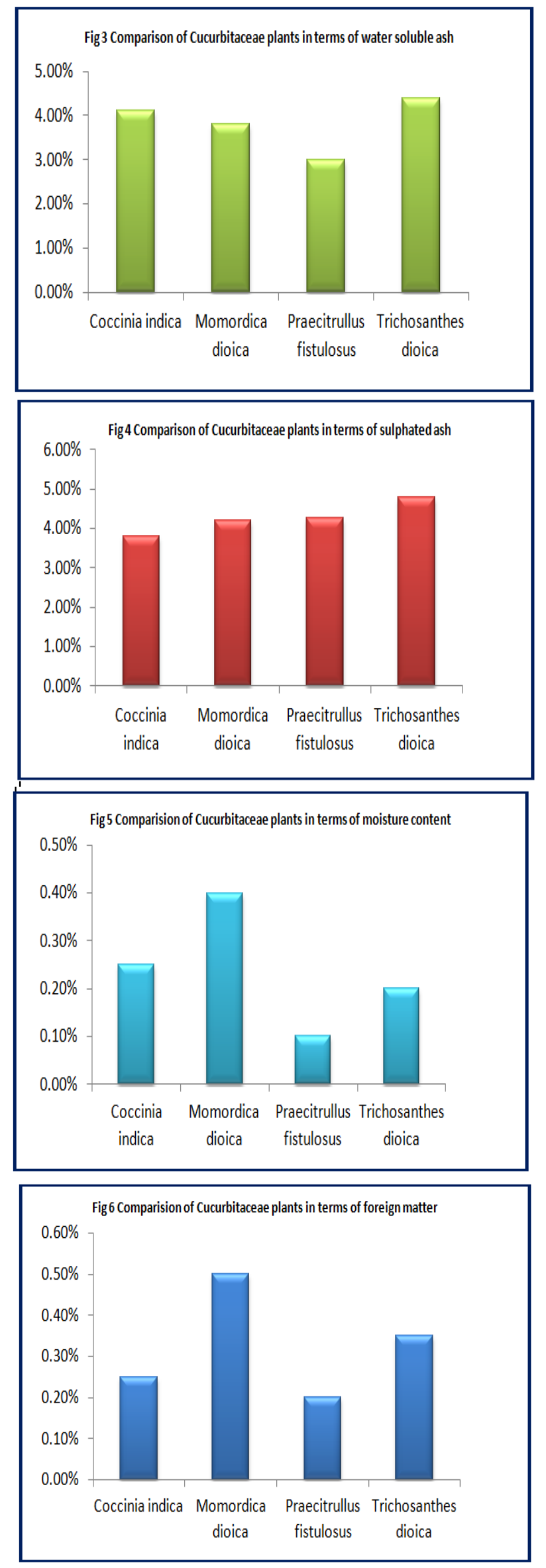


\section{CONCLUSION}

Authenticity, purity and assay are important attributes for assuring the quality and standardization of herbal drugs. The present study may be useful to supplement information in respect to its identification, authentication and standardization of herbal drugs. In other words, the physicochemical features examined in the present study may serve as tool for identification of the plant for validation of the raw material and for standardization of its formulations at herbal industrial level in the coming days [10]. Today sophisticated modern research tools for evaluation of the plant drugs are available but physicochemical method is still one of the simplest and cheapest methods to start for establishing the correct identity of the source materials. Hence, physicochemical evaluation of different cucurbitaceae medicinal plants will help in identifying the crude drug as potent therapeutic agents.

\section{ACKNOWLEDGEMENT}

The author Yogesh Shivhare is thankful to the management of Sarvepalli Radhakrishnan University for providing necessary facilities for completion of this work. The author is also express my special gratitude to my colleagues Dr. Prashant Soni and Mr. Pratyush Jain for their encouragement and motivation always.

\section{REFERENCES}

1. Rubatzky VE and Yamaguchi Mas. World Vegetables, Principles, Production and nutritive value. $2^{\text {nd }}$ Edition, Chapman and Hall, U. S.A. 1997; 577-639.

2. Hutchinson J and Dalziel JM. Flora of West Tropical Africa. Crown Agents, London. 1954.

3. Saha D, Pahari SK, Maity T, Sur D. Pharmacognostic studies of the bark of Parkinsonia aculeata. International Journal of Pharmaceutical Sciences \& Research. 2010; 1 (11):473-475.

4. Modi DC, Patel JK, Shah BN, Nayak BS. Pharmacognostic studies of the seed of Syzygium cumini linn. International Journal of Pharmceutical Science. 2010; 1 (1):20-26.

5. Kadam PV, Deoda RS, Shivatare RS, Yadav KN, Patil MJ. Pharmacognostic, phytochemical and physiochemical studies of Mimusops elengi Linn stem bark (Sapotaceae). Schol Res Library. 2012; 4 (2):607-613.

6. Kumar S, Kumar V, Prakash O. Microscopic evaluation and physiochemical analysis of Dillenia indica leaf. Asian pacific journal of tropical biomedicine. 2011; 1(5):337.

7. Khandelwal KR. Practical Pharmacognosy Techniques and Experiments. $15^{\text {th }}$ edition. India, Nirali Prakashan,Pune. 2006; 15-163.

8. Kokate CK, Purohit AP, Gokhale SB. Pharmacognosy. 22 ${ }^{\text {nd }}$ Edition. Nirali Prakashan Pune. 2003; 109- 257.

9. Kokate CK. Practical Pharmacognosy. 4th Edn, Vallabh Prakashan, Delhi. 1997; 107-111.

10. Kadam PV, Yadav KN, Narrapanawar NS, Shivatare RS, Bhusnar HU, Patil MJ. Development of quality standards of Terminalia catappa leaves. Pharmacognosy Journal. 2011; Vol. 3, 26, 19-26. 